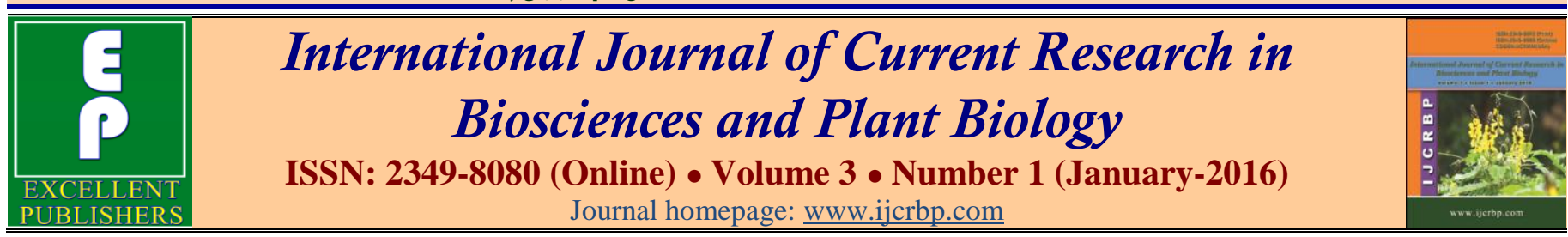

\title{
Multiple Rust Resistance in Triticum aestivum, T. durum, T. dicoccum and Triticale
}

\author{
D. P. Singh ${ }^{1 *}$, A. K. Sharma1 ${ }^{1}$ Indu Sharma ${ }^{1}$ Ishwar Singh', M. S. Saharan ${ }^{1}$, Madhu Meeta ${ }^{2}$, \\ Satvinder K. Mann², K. P. Singh3, J. Kumar's, Deepshikhas, Kanak Srivastava3, U. D. Singh4, \\ V. C. Sinha, ${ }^{4}$ S. S. Karwasra ${ }^{5}$, M. S. Beniwals, S. K. Jain ${ }^{6}$, S. K. Pant ${ }^{6}$, A. N. Misra7, \\ I. K. Kalappanawar8, V. K. Shinde9, B. P. Kurundkar', R. T. Sapkal9, R. K. Bansal' ${ }^{10}$, \\ V. L. Majumdhar ${ }^{10}$, P. S. Shekhawat ${ }^{10}$, R. N. Brahma ${ }^{11}$ and Jagdish Kumar'11
}

${ }^{1}$ Indian Institute of Wheat and Barley Research, Karnal-132 oo1, Haryana, India

${ }^{2}$ Department of Plant Pathology, Punjab Agricultural University, Ludhiana, Pubjab, India

3Department of Plant Pathology, Govind Ballabh Pant University of Agriculture \& Technology, Pantnagar-263 145, Uttarakhand, India

$4(V C S) \&(U D S)$ Division of Genetics and Plant Breeding, Division of Mycology \& Plant Pathology, IARI, New Delhi-110 o12, India

5 Department of Plant Pathology, CCS Haryana Agricultural University, Hisar-125 004, India

${ }^{6}$ Vivekananda Parvatiya Krishi Anusandhan Sansthan, Dugalkhola, Almora, Uttarakhand-263 601, India

7 IARI Research Station, Indore, Madhya Pradesh-452 oo1, India

${ }^{8}$ Dr. Sanjay Rajaram Wheat Laboratory, University of Agricultural Sciences, Dharwad-580 oo5, Karnataka, India

${ }_{9}$ MPKV Rust Laboratory, Mahabaleshwar-412 806, Maharashtra, India

${ }^{10}$ Department of Plant Pathology, RAU Research Station, Durgapura, Jaipur-302 018, India

${ }^{11}$ IARI Research Station, Wellington- 643 231, Tamil Nadu, India

*Corresponding author; Present Address: Guyana Rice Development Board, 116-117, Cowan Street, Kingston, Georgetown, Guyana

\begin{abstract}
Wheat and Triticale rusts (leaf stem and stripe) are important diseases in India and other South Asian countries and in regions of world wherever wheat is cultivated. Rusts are known to evolve over time and space and thus making it necessary to breed new wheat and Triticale genotypes with new combination of resistant genes to rusts for effective management of this menace. In India, the evaluation of newly developed wheat varieties against three rusts initiates even before their entry in to the coordinated yield trials besides, evaluation of these in initial and advanced varietal trials at hot spot locations under artificially inoculated conditions. The numbers of resistant entries of the yield trials, identified against three (stem, leaf and stripe) or two rusts (stem and leaf or leaf and stripe) and falling in the range of average coefficient of infection from 0-10.0 in Plant Pathological Screening Nursery (PPSN) were again tested to confirm their resistance during 2003-04 till 2011-12 crop seasons at hot spot locations: Mahableshwar, Wellington, Indore, Dharwad against stem rust, Hisar, New Delhi, Karnal, Ludhiana, Pantnagar, Durgapura in North, Mahableshwar, Indore, Wellington and Dharwad in South against leaf rusts whereas, Karnal, Pantnagar, Durgapura, Almora and Ludhiana in North India, against stripe rust. These lines have wide genetic base and those identified in AVTs are quite good in agronomic characters. Out of 741 genotypes tested, 460 numbers were found to possess multiple rust resistance. A total of 315 were resistant to stem, leaf and stripe rusts, 90 to stem and leaf rusts and 55 to leaf and stripe rusts. Out of these, 364 of bread wheat (T. aestivum), 71 of macaroni wheat (T. durum), 11 of khapali wheat (T. dicoccum) and 14 genotypes of Triticale were resistant to two or three rusts. These include both types of genotypes falling in the category of ACI 0.0-5.00 and 5.110.0 and are used in breeding for rust resistance in India. A total of 20 such genotypes are already released as high yielding rust resistant varieties in India. The seeds of these are kept in gene banks of IIWBR, Karnal and National gene bank at NBPGR, New Delhi.
\end{abstract}

\section{Article Info}

Accepted: 09 December 2015

Available Online: 06 January 2016

\section{Keywords}

Multiple rust resistance

Puccinia recondita

P. striiformis f. sp. tritici

P. graminis f. sp. tritici

Wheat rust 


\section{Introduction}

Leaf (Puccinia triticina Eriks.), stripe $\quad(P$. striiformis West. f. sp. tritici Eriks. \& E. Henn.) and stem rust ( $P$. graminis Pers. f. sp. tritici Eriks. \& E. Henn) are the major diseases of concern in wheats (Triticum aestivum, T. durum and T. dicoccum) and Triticale in India and other South Asian Countries. Rusts are present worldwide (Singh et al., 2015). Since rusts are multiple interest disease therefore deployment of resistant varieties is most effective and preferred means of their management in field (Bahadur et al., 1994). The breeding for rust resistance in wheat and it is a continuous process since new pathotypes of rusts keep evolving over time thus making old varieties rust susceptible (Saari and Nayar, 1998). No all rusts are having equal importance in a particular agro ecological zone in India and their severity and damage varies. The leaf and stripe rusts are of major concern in northern hills and north-western plains zones whereas leaf and stem rusts are of much importance in central and peninsular India. Likewise, in north-eastern plains zone, leaf rust is of major importance. In southern hill zone, all three rusts are of importance. Thus, the leaf rust is important for all the wheat growing zones of the country. However, leaf rust pathotype spectrum in northern, central and peninsular region in India varies. The varieties like HD 2285 and HD 2329 which were quite popular during eighties and early nineties are no longer able to sustain their yield potential due to susceptibility to new pathotypes and thus suffer yield losses up to $25.8 \%$ due to leaf rust (Singh, 1999). Hence these have been replaced by new resistant varieties like PBW 343, HD 2687, UP 2425, DBW 14, etc. during twenties. Hakim and Yahaoui (2003) studies the presence of physiological races of wheat yellow rust Puccinia striiformis f. sp. tritici Eriks and their virulences in Syria and Lebanon and reported that race 230 E150 was the most virulent and can overcome 14 resistant genes $(\operatorname{Yr} 6,7, \mathrm{SD}, 9+, 7+, 6+, 8,2+, \mathrm{A}, 2,9,17$ and 18). Nayar et al. (2003) reported 15 lines resistant to leaf rust, while none was resistant to all pathotypes in case of stem rust in 50 durum lines tested. This has emphasized the identification of new donor lines with multiple rust resistance and diverse genetic base for the use in breeding for rust resistance.

\section{Materials and methods}

A nursery namely 'Elite Plant Pathological Screening Nursery (EPPSN)' consisting of resistant genotypes identified in AVTs was planted at hot spot locations during 2003-04 to 2011-12 (nine years) crop seasons. A total of 741 numbers of genotypes belonging to Triticum aestivum L.emend Fiori \& Paol., T. durum Derf., and $T$. dococcum Schubl. and Triticale were tested by planting one row of $1 \mathrm{~m}$ length of each genotype. A susceptible check consisting mixture of most susceptible genotypes Bijaga yellow, Sonalika, and Agra local was repeat planted after every twenty test genotypes as well as around the borders of evaluation block. The hot spots are the locations where the environment is very congenial for disease development and sufficient races or variants of pathogen are available in nature. These centres for different rusts were as follows:

Stem and leaf rusts (Central and South): Mahableshwar, Wellington, Indore, Dharwad.

Leaf rust (North): Hisar, New Delhi, Karnal, Ludhiana, Pantnagar, Durgapura.

Stripe rust (North): Karnal, Pantnagar, Durgapura, Almora and Ludhiana.

The most predominant and virulent pathotypes as mentioned below were used for artificial inoculation on infector lines quite early in the season (Dec- Feb.). These along with their initial source of availability are as below:

\section{Stem rust pathotypes}

Flowerdale (Shimla in North)

11(79G31), 40A (62G29), 42 (19G35), 122(7G11), 1176 (37G19).

\section{Mahabaleshwar (In South)}

11 (79G31), 40A (62G29), 42 (19G35), 122(7G11), 1176 (37G19).

\section{Leaf rust pathotypes}

Flowerdale (Shimla)

12-2 (1R5), 77-2(109R31-1), 77-5 (121R63-1) and 1042 (21R55).

Mahabaleshwar

12-2 (1R5), 77-2(109R31-1), 77-5 (121R63-1) and 1042 (21R55).

\section{Stripe rust pathotypes}

Flowerdale (Shimla)

K (47S102), P(46S103), L(70S69), 13(67S8), 46S119 and $78 \mathrm{~S} 84$. 
The inoculation was done using syringe as well as foliar sprays by taking mixture of freshly harvested uredospores of different pathotypes of each rust separately@10 $@ 10^{5}$ per ml. Few drops of Tween 20, a surfactant were also added in spore suspension to keep proper homogeneity. The sprays were made in afternoon time from 3-4 pm to ensure that leaves are not having dew and take advantage of night time dew to facilitate spore germination and infection process. Further spread of rust spores was ensured by spraying of water on the spreader rows and by maintaining proper moisture conditions in screening block.

The rust records are taken from flowering to hard dough stage and terminal disease score was taken in to consideration and was taken in modified Petersons' scale (Joshi et al., 1988). The recording of rusts was based on both severity of disease on plant parts $(1,5,10,20,30$, $40,50,60,70,80,90$ and 100\%) as per Peterson et al. (1948) and the host response was recorded as 0-No visible infection, R-Resistant, MR-Moderately resistant, X-Intermediate, MS-Moderately susceptible, SSusceptible. The coefficient of infection (CI) was calculated by multiplying the percentage of infection by a 'response value' assigned to each infection type (Loegering, 1959). The average CI (ACI) and highest score was calculated for each genotype and these were used to categorize the level of resistance. The genotype possessing the ACI 0-10 for three rusts or two rust were selected as multiple rust resistant.

\section{Results}

Out of 741 genotypes tested, 460 numbers were found to possess multiple rust resistance. A total of 315 were resistant to stem, leaf and stripe rusts, 90 to stem and leaf rusts and 55 to leaf and stripe rusts. Out of these, 364 of bread wheat (T. aestivum), 71 of macaroni wheat ( $T$. durum), 11 of khapali wheat (T. dicoccum) and 14 genotypes of Triticale, were resistant to two or three rusts. The range of ACI and highest scores in infector to stem, leaf rust in north and south and stripe rusts was quite high and given below:

Stem rust (South): ACI range: 56.7-83.3, Highest score range: $80 \mathrm{~S}-100 \mathrm{~S}$.

Leaf rust (North): ACI range: 46.7-85.0 Highest score range: $60 \mathrm{~S}-100 \mathrm{~S}$.

Leaf rust (South): ACI range: 63.0-93.3, Highest score range: $80 \mathrm{~S}-100 \mathrm{~S}$.
Stripe rust (North): ACI range: 56.0-82.0 Highest score range: $60 \mathrm{~S}-100 \mathrm{~S}$.

The details of genotypes along with their highest scores and ACI are given in Table 1. A total of 281 genotypes were turned susceptible to rusts, during evaluation and these were deleted from the list. It includes those having resistance to stem and stripe rusts since these are rarely used. Also any genotype possessing resistance to two diseases but high susceptibility to one rust ( $>60 \mathrm{~S}$ highest score) were also dropped from list of multiple rust resistant genotypes identified.

All resistant genotypes listed in Table were having resistance to major leaf rust pathotypes in prevailed in both Northern and Southern parts of India. The parentage and listing of resistant genes in these multiple rust resistant genotypes (Table 1) are available in annual reports of crop protection of All India Coordinated Wheat and Barley Improvement Programme (2003-04 to 2011-12) at IIWBR Karnal and all the wheat and Triticale Coordinated Centres in India. The seed of these resistant genotypes to rusts are stored safely in gene banks at NBPGR New Delhi and IIWBR Karnal in India. Most of the lines identified are of high yielding in nature and were selected from final years of testing and may be used as resistant sources in breeding programme against rusts. Few are now released in India for cultivation. The genotypes having resistance to leaf and stripe rusts are also good for northern hill and plains as well eastern India whereas those showing resistance to only stem and leaf rust may be of use in central and peninsular India. The genotypes have been categorized in to two broad categories based on ACI. The one which is having resistant genes effective against particular pathotypes and effective at all stages of plant growth (ACI 0.0-5.0). The second category of genotypes may be having adult plant resistant genes which are effective against wide range of pathotypes at adult stage (ACI 5.1-10.0).

There are range of varieties, which may be having low ACI value (5-10) in spite of high rust score at 1-2 test locations, and some are showing narrow range of ACI. This may be due to presence of slow rusting genes as well as expression of resistant/ susceptibility genes at different locations due to change in temperature during adult stage. A total of 201 entries having varied genetic base have been included in the National Genetic Stock Nursery (NGSN) and sent for utilization at 36 numbers of wheat breeding centers across India for utilization in breeding for resistance programme in wheat and barley. 
Table 1. Multiple rust resistant genotypes of wheats and Triticale identified through multi location hot spot testing from $2003-04$ till 2011-12 crop seasons.

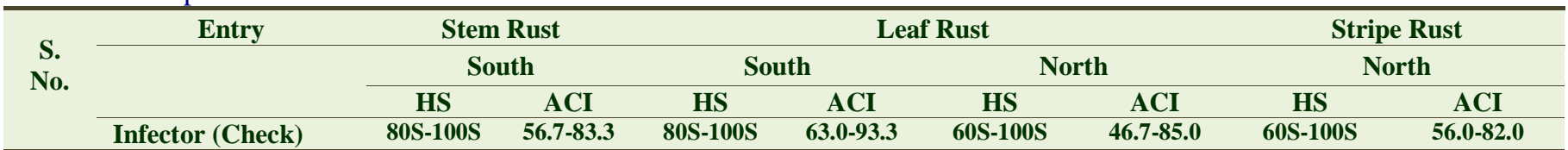

1. Resistant to stem, leaf and stripe rusts

a.(ACI 0.0-5.0)

T. aestivum (Bread wheat)

DBW 28, DBW 31, DBW 37, DBW 50, DBW 51, DBW 54, DBW 58, DBW 60, DBW 62, DBW 71, HD 2837, HD 2866, HD 2891, HD 2964, HD 2997, HD 2998, HD 3002, HD 3007, HI 1535, HI 1563 (c), HI 1569, HP 1872, HP 1903, HPW 224, HPW 226, HPW 237, HPW 240, HPW 267, HPW 277, HPW 285, HPW 287, HPW 296, HPW 308, HPW 317, HPW 347, HPW 348, HPW 349, HPW 360, HPW 361, HS 456, HS 460, HS 461, HS 471, HS 472, HS 490 (c), HS 507, HS 508, HS 513, HS 522, HS 525, HS 533, HS 544, HS 545, HUW 620, HUW 626, HUW 629, HUW 635, HUW 636, HUW 638, HW 5209, HW 5010, HW 5021, HW 5028, HW 5030, HW 5202, HW 5205, HW 5206, HW 5207 (c), HW 5208, HW 5209, HW 5210, K 0615, KRL 240, KRL 249, KRL 250, MACS 3815, MACS 3828, MACS 6273, MP 3223, MP 3288, NW 4091, PBW 530, PBW 559, PBW 549, PBW 580, PBW 581, PBW 582, PBW 588, PBW 589, PBW 590 (c), PBW 593, PBW 599, PBW 605, PBW 612, PBW 617, PBW 621, PBW 625, PBW 626, PBW 629, PBW 640, PBW 658, PBW 659, RAJ 4120 (c), RAJ 4124, RAJ 4125, RAJ 4130, RAJ 4176, RAJ 4201, RAJ 4205, RW 3673, UAS 295, UP 2600, UP 2626, UP 2642, UP 2696, UP 2719, UP 2763, UP 2771, UP 2798, VL 849, VL 864, VL 865, VL 892 (c), VL 895, VL 900, VL 907 (c), VL 912, VL 913, VL 920, VL 922, VL 926, VL 931, VL 934, VL 941, VL 943, VL 955, VL 956, WH 1023, WH 1043, WH 1061, WH 1062, WH 1076, WH 1078, WH 1094 , WH 1095 (Total: 145)

T. durum (Macaroni wheat)

AKDW 3795-3, DDW 11, HD 4720, HI 8638, HI 8671, HI 8672, HI 8678, HI 8680, HI 8682, HI 8692, HI 8696, HI 8699, HI 8702, HI 8703, HI 8704, HI 8708, HI 8709, MACS 3742, MACS 3744, MPO1215(c), PDW 295, PDW 307, UAS 419, UAS 432,WHD 948 (Total: 25)

Triticale

TL 2908, TL 2930, TL 2934, TL 2935, TL 2942 (c), TL 2945, TL 2955, TL 2963, TL 2966, TL 2968, TL 2969, TL 2975 (Total: 12)

\section{b. (ACI 5.1-10.0)}

T. aestivum (Bread wheat)

CBW 23, DBW 15, DBW 16 (c), DBW 17, DBW 18, DBW 30, DBW 52, GW 349, GW 385, HD 2826, HD 2868, HD 2888 (c), HD 2922, HD 2944, HD 2962, HD 2963, HD 2982, HD 2987, HD 3071, HI 1579, HPW 223, HPW 236, HPW 241, HPW 245, HPW 251, HPW 254, HPW 298, HPW 371, HPW 731, HS 443, HS 446, HS 459, HS 463, HS 468, HS 473, HS 484, HS 485, HS 512, HS 534, HS 526, HS 541, HS 542, HUW 567, HUW 595, HUW 598, HUW 625, HUW 640, HW 5001, HW 5005, HW 5013, HW 5037, HW 5213, JKW 2, K 0124, K 0707, K 0803, KRL 210 (c), KRL 273, KRL 238, KRL 239, KRL 251, MP 3173, NW 3087, NW 4081, PBW 493, PBW 509, PBW 524, PBW 525, PBW 543, PBW 547, PBW 550 (c), PBW 554, PBW 578, PBW 611, PBW 615, PBW 635, RAJ 4041, RAJ 4083 (c), RAJ 4161, RAJ 4164, RAJ 4188, RAJ 4237, RAJ 4235, RSP 561, RSP 566, SKW 441, UAS 305, UAS 324, UAS 327, UP 2601, UP 2621, UP 2632, UP 2645, UP 2647, UP 2687, UP 2691, UP 2711, UP 2747, UP 2748, VL 829 (c), VL 858, VL 867, VL 868, VL 875, VL 890, VL 894, VL 898, VL 902, VL 905, VL 930, VL 944, WH 773, WH 1021 (c) (Total: 113)

T. durum (Macaroni wheat)

AKDW 4021, CDW 04, GW 1189, GW 1255, HD 4696, HI 8627(c), HI 8690, HI 8722, MPO 1226, MPO 1243, NIDW 309, NIDW 577, PDW 311, PDW 312, PDW 316, UAS 414, UAS 428, UPD 85 (Total: 18)

Triticale

DT 132, TL 2949 (Total: 2)

\section{Resistant to stem and leaf rusts only}

\section{a. ACI 0.0-5.0 for stem and leaf rusts, ACI for stripe rust ranges 0.0-36.8}

T. aestivum (Bread wheat) GW 384, HD 2933, HD 2934, HD 2937, HD 2952, HD 2956, HD 2957, HD 2959, HD 2986, HI 1531, HI 1544, HUW 608, HW 2065, HW 2308, HW 3038, HW 3070, HW 3080, HW 3094, HW 4055, HW 5015, HW 5018, HW 5027, HW 5042, HW 5044, HW 5102, HW 5103, HW 5104, HW 5301, HW 5304, JKW 20, K 0204, KRL 213 (c), LOK 59, MACS 2959, MACS 2980, MP 1194, MP 1200, NIAW 1343, PBW 568, PBW 573, PBW 574, PBW 575, PBW 583, PBW 585, RAJ 4101, RAJ 4119, RAJ 4131, RAJ 4132, USA 259 (Total: 49) 
T. durum (Macaroni wheat)

GW 1244, MACS 3598 (Total: 2)

T. dicoccum (Khapli or Emmer wheat)

DDK 1033, DDK 1036, HW 1096, HW 1095, HW 1097, MACS 2956 (Total: 6)

b. ACI 5.0-10.0 for stem and leaf rusts, ACI to stripe rust ranges- 0.2-33.8

T. aestivum (Bread wheat)

DBW 32, DDK 1025, DDK 1029 (c), GW 373, HD 2906, HD 2946, HD 2954, HD 2955, HD 2978, HD 2989, HI 1552, HS 424,

HS 492, HS 493, HW 3037, K 0101, LOK 54, MACS 6198, MP 1556, NIAW 1188, PBW 587, RAJ 4129, UAS 304, UP 2644, UP

2683, UP 2689 (Total: 26)

T. durum (Macaroni wheat)

GW 1236, GW 1240 (Total: 2)

T. dicoccum (Khapli or Emmer wheat)

MACS 2963, MACS 2971, MACS 2981, MACS 2984, MACS 2985 (Total: 5)

3. Resistant to leaf and stripe rust only

a. ACI 0.0-5.0 for leaf and stripe rusts, ACI to stem rust ranges 2.3-29.5

T. aestivum (Bread wheat)

CBW 38, DBW 41, HP 1911, HUW 555, HW 4028, K 0811, MP 1201, UP 2663, UP 2665, VL 891, VL 924, WH 1080 (Total: 12)

T. durum (Macaroni wheat)

DDW 16, DDW 19, HD 4722, HI 8713, MPO 1204, MPO 1220, NIDW 319, NIDW 370, NIDW 505, PDW 313, PDW 322, PDW 324, PDW 325, RKD 142, RKD 216, WHD 946 (Total:16 )

b. ACI 5.1-10.0 for leaf and stripe rusts, ACI to stem rust ranges 1.4-34.0

T. aestivum (Bread wheat)

AKAW 4635, HD 2830, HD 2834, HS 444, HS 491, HS 502, HPW 211, HPW 238, HUW 639, JKW 37, MACS 3424, NW 2069, NW 3073, RW 3686, UAS 410, UP 2596, VL 901, VL 921, VL 925 (Total: 19)

T. durum (Macaroni wheat)

AKDW 2997-16 (c), AUKD -3, DDW 12, DDW 15, HD 4717, NIDW 325, PDW 314, UAS 431(Total: 8)

c- Released varieties, HS- Highest score, ACI- Average Coefficient of Infection.

\section{Discussion}

The The present study done at multiplications suggests that combined resistance to three or two rusts is quite possible in breeding for rust resistance in wheat ( $T$. aestivum, T. durum and T. dicoccum) and Triticale even by traditional breeding approach and deployment of multiple rust resistant varieties is effectively manage the disease. Bahadur et al. (1994) proposed a revised strategy for managing stem and leaf rusts of wheat, caused by Puccinia graminis f. sp. tritici and $P$. recondita f.sp. tritici, respectively, in six different ecological areas of India. The use of horizontal resistance/slow rusting varieties is re-advocated in areas 1 (Tamil Nadu) and 6 (Jammu and Kashmir, Himachal Pradesh, and hilly areas of Uttar Pradesh) by them. Hisbanis et al. (2003) reported ten wheat cultivars, B. Yellow, C 306, GW 173, HD 2189, HD 2501, HD 2687, K 8962, PBW 396, Sujata and WH 542 had low AUDPC against leaf rust. There may be two possibilities of slow and fast rusters. With an advancement of leaf rust, availability of green tissue for further disease development went on diminishing in fast rusters whereas in slow rusters, resistance mechanism is activated and further spread and development of mycelium is restricted. Kang et al. (2003) studied the relationship of host resistance and histological and cytological features between incompatible combinations of wheat cultivars and stripe rust pathogen. The main histological manifestations of pathogen development in the resistant wheat cultivars include inhibition of fungal growth, delay in hyphal branching and colony formation, decrease in formation of haustorial mother cells and haustoria and occurrence of host cell necrosis. The structural defense reactions such as formation of cell wall apposition, collar and encasement of haustorium were more pronounced in the infected wheat leaves of the resistant than the susceptible cultivars. Agarwal et al. (2003) investigated the effect of temperature on rust reactions of wheat cultivars and found differential expression of $\operatorname{Lr} 34$, a leaf rust resistant gene in RL 6058 
and RL 6061 at 15 and $20{ }^{\circ} \mathrm{C}$ which may be due to additional genes in these accessions.

The rusts in wheat are still able to infect the susceptible wheat and regular transfer of resistant genes which are effective against newer pathotypes of three leaf, stem and stripe rust depending on the degree of risk of different rusts in a particular agroclimatic zone in India and adjoining SAARC countries is necessary to avoid any major rust epidemic in future. Marasas et al. (2003) reported the economic impact of productivity maintenance research with reference to breeding for leaf rust resistance in modern wheat. The internal rate of return on CIMMYT's research investment since 1973 was estimated $41 \%$. When discounted by $5 \%$, the present value was US\$ 5.36 billion in 1990 dollars, and the benefit-cost ratio was 27:1. These findings emphasize the economic importance of maintenance research in crop breeding programme. More research is advocated on adult plant genes along with $\mathrm{R}$ genes and their mechanism of action, when these are stacked in a wheat genotype in combination by Ellis et al. (2014).

Gurjar et al. (2012) tested twenty five Indian wheat genotypes against diverse nine pathotypes of stem, leaf and stripe rusts. The most commonly postulated stem resistance genes in seedlings were $\mathrm{Sr} 31$ and $\mathrm{Sr} 2$. The presence of $\mathrm{Sr} 2(40 \%)$ was observed in ten genotypes viz., HD 2894, HD 2687, VL 616, UP 2425, Raj 3765, HI 1531, HI 977, DBW 16, PBW 343 and WL $711(+\operatorname{Lr} 57)$. The presence of $\operatorname{Sr} 31(36 \%)$ and $\operatorname{Lr} 26$ (36\%) was observed in nine genotypes viz. HD 2687, HD 2733, HD 2824, VL 804, UP 2425, DBW 17, PBW 343, PBW 550 and HS 240 followed by Lr13 (28\%), Lr34 (24\%), Lr23 (20\%) and Lr24 (12\%). Resistant type reaction showed the presence of $L r 24$ gene in HD 2888, HI 1531and HW 2004 against four pathotypes of leaf rust viz. 77-5, 77-8, 104-2, 12-1. $\mathrm{Yr} 9$ gene was observed in nine genotypes (36\%), HD 2687, HD 2733, HD 2824, VL 804, UP 2425, DBW 17, PBW 343, PBW 550 and HS 240 followed by $Y r 2$ (28\%) and $\operatorname{Yr} 18(20 \%)$. There appears to be enough genetic variability in resistant and agronomically superior genotypes of wheat and Triticale which may be exploited by the breeders in breeding for rust resistant varieties. Sharma et al. (2015) tested popular varieties of wheat in East Africa (Kenya and Ethiopia) against stem rust (Puccinia graminis f. sp. tritici) pathotype Ug99 and its variants.

Wheat lines, viz. A-9-30-1, AKDW 4021, DDK 1037, DDK 1038, DDW 14, DL 153-2, GW 1250, HD 2781,
HD 3014, HD 4720, HDR 77, HI 8381, HI 8498, HUW 234, HW 5211, K 9107, MACS 1967, MACS 2846, MACS 2988, MACS 2998, MACS 3742, MACS 5009, MPO 1215, NI 5439, NIDW 295, PBW 315, PBW 612, PDW 274, PDW 316, PDW 317, WH 147, and Triticale varieties TL 2942, TL 2963 and TL 2966, showed resistance to Ug99 and its variants (Ug99TTKS and TTKSK) during 2006-2011. These identified multiple rust resistant genotypes mentioned in Table 1 may also be further tested against emerging pathotypes like Ug 99 of stem rust using phenotypic and molecular techniques. There are good possibilities that few of these may be resistant to Ug 99 pathotype of stem rust. A strong breeding programme of wheat and Triticale and India supported by plant pathologists have really paid dividends and did not allow the wheat rusts to appear in epidemic form since past five decades. The identified genotypes may be used for breeding to bring desired level of resistance in future in India and other SAARC countries. These lines may be used in future for cellular and molecular studies to find out the mechanism of action of resistant genes in combination and understand the host pathogen interaction better.

\section{Conflict of interest statement}

Authors declare that they have no conflict of interest.

\section{References}

Agarwal, S., Sharma, A. K. Saini, R.G., 2003. Seedling reaction of Thatcher (Triticum aestivum L.) near isogenic lines with adult plant leaf rust resistance genes Lr34 and Lr37. Wheat Info. Serv. 97, 21-22.

Bahadur, P., Singh, D.V., Srivastava, K. D., 1994. Management of wheat rusts: a revised strategy for gene deployment. Indian Phytopath. 47, 41-47.

Ellis, G. J., Lagudah, S. E., Spielmeyer, W., Dodds, N. P., 2014. The past, present and future of breeding rust resistant wheat. Front. Plant Sci. 5, 1-12. (article 641).

Gurjar, M. S., Aggarwal, R., Prashar, M., 2012. Phenotyping of Indian wheat (Triticum aestivum) genotypes for identification of rust resistance genes. Indian Phytopath. 65: 345-348.

Hakim, M. S., Yahaoui, A., 2003. The physiological races of wheat yellow rust Puccinia striiformis f. sp. tritici Eriks and their virulences in Syria and Lebanon. Arab J. Pl. Prot. 21, 12-18.

Hisbanis, S. N., Joi, M. B., Shinde, V. K., Ilhe, B. M., 2003. Adult plant response of wheat varieties against leaf rust (Puccinia recondita f. sp. tritici). Agric. Sci. Dig. 23, 6-9.

Joshi, L. M., Singh. D. V., Srivastava, K. D., 1988. Manual of Wheat Diseases. Molhotra Publishing House, New Delhi. $75 \mathrm{p}$. 
Kang, Z., Wang, Y., Huong L., Wei, G., Zhao, J., 2003. Histology and ultra structure of incompatible combination between Puccinia striiformis and wheat cultivars with resistance of low reaction type. Sci. Agric. Sinica. 36, 1026-1031.

Loegering, W. O., 1959. Method for Recording Cereal Rust Data. USDA, International Spring Wheat Nursery. 10p.

Marasas, C. N., Amale, M., Singh, R. P. 2003. The economic impact of productivity maintenance research: breeding for leaf rust resistance in modern wheat. Agric. Econ. 29, 253263.

Nayar, S. K., Bhardwaj, S. C., Prashar, M., Rao, V. S. P., Singh, S. B., 2003. Resistance to black and brown rusts in some advanced lines in durum wheat in India. Pl. Dis. Res. 18, 110-114.

Peterson, R. F., Cambell, A. B., Hannah, A. E., 1948. A diagrammatic scale for estimating rust intensity of leaves and stem of cereals. Can. J. Res. Section C: Bot. Sci. 26, 496-500.
Saari, E. E., Nayar, S.K., 1998. Experience with wheat rusts in South Asia. In: Wheat: Research Needs Beyond 2000 AD (Eds.: Nagarajan, S., Singh, G., Tyagi, B.S.). Narosa Publishers, New Delhi, India. pp. 177-190.

Sharma, A. K., Saharan, M. S., Bhardwaj, S. C., Prashar, M., Chatrath, R., Tiwari, V., Mangal Singh, Indu Sharma, 2015. Evaluation of wheat (Triticum aestivum) germplasm and varieties against stem rust (Puccinia graminis f. sp. tritici) pathotype Ug99 and its variants. Indian Phytopath. 68, 1143-138.

Singh, D. P. 1999. Assessment of losses due to brown rust in two popular cultivars of wheat. Pl. Dis. Res. 14, 60-62.

Singh, R. P., Huerta-Espino, J., Roelfs, A. P. 2015. The wheat rusts. FAO Document Repository. http://www.fao.org/ docrep/006/y4011e/y4011e0g.htm.

\section{How to cite this article:}

Singh, D. P., Sharma, A. K., Indu Sharma, Ishwar Singh, Saharan, M. S., Madhu Meeta, Mann, S.K., Singh, K. P., Kumar, J., Deepshikha, Kanak Srivastava, Singh, U. D., Sinha, V. C., Karwasra, S. S., Beniwal, M. S., Jain, S. K., Pant, S. K., Misra, A. N., Kalappanawar, I. K., Shinde, V. K., Kurundkar, B. P., Sapkal, R. T., Bansal, R. K., Majumdhar, V. L., Shekhawat, P. S., Brahma, R. N., Jagdish Kumar, 2016. Multiple rust resistance in Triticum aestivum, T. durum, T. dicoccum and Triticale. Int. J. Curr. Res. Biosci. Plant Biol. 3(1), 46-52. doi: http://dx.doi.org/10.20546/ijcrbp.2016.301.005 